\title{
Establishment of Combustion Model for Isooctane HCCI Marine Diesel Engine and Research on the Combustion Characteristic
}

\author{
Biao $\mathrm{Li}^{1,}$ a and Hongtao Gao ${ }^{1}$ \\ ${ }^{1}$ The College of Marine Engineering, Dalian Maritime University, 116026, Dalian, China
}

\begin{abstract}
The homogeneous charge compression ignition (HCCI) combustion mode applied in marine diesel engine is expected to be one of alternative technologies to decrease nitrogen oxide $\left(\mathrm{NO}_{\mathrm{X}}\right)$ emission and improve energy utilization rate. Applying the chemical-looping combustion (CLC) mechanism inside the cylinder, a numerical study on the HCCI combustion process is performed taking a marine diesel engine as application object. The characteristic feature of combustion process is displayed. On this basis, the formation and emission of $\mathrm{NO}_{\mathrm{X}}$ are analyzed and discussed. The results indicate that the HCCI combustion mode always exhibit two combustion releasing heats: low-temperature reaction and high-temperature reaction. The combustion phase is divided into low-temperature reaction zone, high-temperature reaction zone and negative temperature coefficient (NTC) zone. The operating conditions of the high compression ratio, high intake air temperature, low inlet pressure and small excess air coefficient would cause the high in-cylinder pressure which often leads engine detonation. The low compression ratio, low intake air temperature and big excess air coefficient would cause the low combustor temperature which is conducive to reduce $\mathrm{NO}_{\mathrm{X}}$ emissions. These technological means and operating conditions are expected to meet the $\mathrm{NO}_{\mathrm{x}}$ emissions limits in MARPOL73/78 Convention-Annex VI Amendment.
\end{abstract}

\section{Introduction}

Since the first industry revolution, diesel engine was used on ship and has contributed significantly to shipping industry. At the same time, environment pollution problem caused by harmful emissions especially the nitrogen oxide $\left(\mathrm{NO}_{\mathrm{X}}\right)$ from marine diesel engine is more serious, which have attracted wide international attention [1]. Convention-Annex VI Amendment to MARPOL73/78 worked out by the International Maritime Organization (IMO) for the prevention of air pollution from ships has became effective on May 19, 2005. In addition, in October 2008, the Marine Environmental Protection Committee (MEPC) of IMO agreed upon progressively stricter limitations for $\mathrm{NO}_{\mathrm{X}}$ emissions from vessels based on their date of engine installation with the standards of Tier I, Tier II and Tier III. These standards have taken effect beginning on July 1, 2010.

As shown in Table 1, the Tier III standard is the strictest mandatory requirement applied for the engine of which installation date is later than January 1, 2016 in designated Emission Control Areas (ECA). And the Tier II requirement is still performed outside the ECA. Compared with the requirements of Tier II and Tier I, $\mathrm{NO}_{\mathrm{X}}$ emissions must decrease by $74 \%-79 \%$ and $80 \%$ respectively to meet the Tier III requirement.
Table 1. $\mathrm{NO}_{\mathrm{X}}$ emissions limits in MARPOL73/78 ConventionAnnex VI Amendment [1]

\begin{tabular}{|l|c|c|c|}
\hline \multicolumn{1}{|c|}{ Standard } & $\begin{array}{c}\mathbf{n}<\mathbf{1 3 0} \\
/ \mathbf{g} \cdot(\mathbf{k W h})^{-\mathbf{1}}\end{array}$ & $\begin{array}{c}\mathbf{1 3 0} \leq \mathbf{n} \leq \mathbf{2 0 0 0} \\
/ \mathbf{g} \cdot(\mathbf{k W h})^{-\mathbf{1}}\end{array}$ & $\begin{array}{c}\mathbf{n}>\mathbf{2 0 0 0} \\
/ \mathbf{g} \cdot(\mathbf{k W h})^{-\mathbf{1}}\end{array}$ \\
\hline Tier I $*$ & 17.0 & $45 \times \mathrm{n}^{-0.2}$ & 9.84 \\
\hline Tier II & 14.36 & $44 \times \mathrm{n}^{-0.23}$ & 7.66 \\
\hline Tier III** & 3.40 & $9 \times \mathrm{n}^{-0.23}$ & 1.97 \\
\hline
\end{tabular}

" $\mathrm{n}$ " refers to rated engine speed $\left(r \cdot \mathrm{min}^{-1}\right)$.

All the $\mathrm{NO}_{\mathrm{X}}$ emissions limits exclude ships with marine diesel engines less than a power output of $130 \mathrm{~kW}$ or ships solely for emergency use such as emergency diesel engine, lifeboat engines etc.

*Annex VI entered into force in 2004, but it applies retroactively to new engines larger than a power output of $300 \mathrm{~kW}$ installed on ships on or after January 1, 2000.

** Tier III applies only in emission control areas.

In the face of the new increasingly stringent $\mathrm{NO}_{\mathrm{X}}$ emission reduction regulations and demand for the higher energy utilization rate. The development and application of effective energy-saving and emission reduction technology adapted in the marine diesel engine are has becoming one of the most basic way [2, 3], except the guidance of the government policies. Homogeneous charge compression ignition (HCCI) is one of the most attractive modes for automotive engines to achieve both high efficiency and low nitrogen oxide $\left(\mathrm{NO}_{\mathrm{X}}\right)$ and particulate matters (PM) $[4,5]$.

The HCCI combustion technology has received increased attention for its potentials of ultra-low $\mathrm{NO}_{\mathrm{X}}$ and PM emissions and high thermal efficiency. A significant

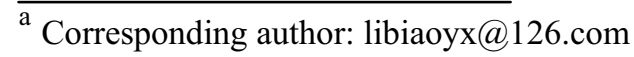


feature of HCCI is that the compression ignitions are happened in multiple regions. Therefore, the temperature inside the combustion chamber is relatively uniform, the cyclic variations are small and there are no hightemperature zones in combustion process. These characteristics can improve the combustion roughness and fuel economy and the formations of $\mathrm{NO}_{\mathrm{X}}$ and $\mathrm{PM}$ are controlled effectively.

Applying the chemical-looping combustion (CLC) mechanism inside the cylinder, a numerical study on the HCCI combustion process is performed taking the MANB\&W6L23/30-A marine diesel engine as application object. The characteristic feature of combustion process is displayed. On this basis, the formation and emission of $\mathrm{NO}_{\mathrm{X}}$ are analyzed and discussed.

\section{Establishment of computational model}

The elementary chemical reactions of diesel combustion in the cylinder are very complex and extremely large in quantity because of the multiple components and uncertainty component concentration in diesel fuel [6, 7]. Consequently, the other single component fuels are always selected as replacements for diesel fuel in combustion simulation. Isooctane is a kind of ideal alternative fuel whose cetane number is approximately of diesel fuel [8].

In this modeling, it is assumed that the thermodynamic pressure, thermodynamic temperature and composition concentration of inflammable mixture are completely uniform in cylinder combustion chamber. The convection heat transfer of cylinder wall is considered, but the radiation heat transfer is ignored. The mixed gas (working fluid) in cylinder, which is from system boundary, and residual exhaust gas are supposed to be thoroughly mixed instantaneously during the intake stroke. The change of cylinder volume caused by piston motion is simplified to a slider-crank mechanism.

\section{Results and analysis}

In the simulation calculation, MAN-B\&W6L23/30-A marine medium-speed diesel engine in marine power plant laboratory of Dalian Maritime University is chosen as the simulation research object. Table 2 shows the structural specifications of MAN-B\&W6L23/30-A diesel Engine [9].

The TDC (Top Dead Center) of the intake stroke is set as the zero point of crank angle $\left(0^{\circ} \mathrm{CA}\right)$. The computational domain starts from the starting point of compression stroke, ends with terminal point of expansion stroke. So the range of crank angle is from $180^{\circ} \mathrm{CA}$ to $540^{\circ} \mathrm{CA}$. The fuel injection way adopts the port fuel injection.

Table.2 Structural specifications of MAN-B\&W6L23/30A diesel Engine

\begin{tabular}{|l|l|}
\hline \multicolumn{1}{|c|}{ Items } & $\begin{array}{c}\text { Specification } \\
\text { parameter }\end{array}$ \\
\hline Cylinder bore $/ \mathrm{mm}$ & 225 \\
\hline Length of stroke/mm & 300 \\
\hline Number of cylinders & 6 \\
\hline Geometry compression ratio & $13: 1$ \\
\hline Connecting rod length $/ \mathrm{mm}$ & 600 \\
\hline Cylinder clearance volume $/ \mathrm{m}^{3}$ & $9.94 \times 10^{-4}$ \\
\hline Release valve open phase degree $/{ }^{\circ} \mathrm{CA}(\mathrm{BDC})$ & -37 \\
\hline Rated speed $/ \mathrm{r} \cdot \mathrm{min}^{-1}$ & 900 \\
\hline
\end{tabular}

Figure 1 is the Heat release rate curve of isooctane HCCI combustion. The curve exhibits two peak values which are the combustion releasing heats of lowtemperature reaction $\left(347^{\circ} \mathrm{CA}\right)$ and high-temperature reaction $\left(354^{\circ} \mathrm{CA}\right)$. The combustion releasing heat of high-temperature reaction accounts for above $95 \%$ of total releasing heat.

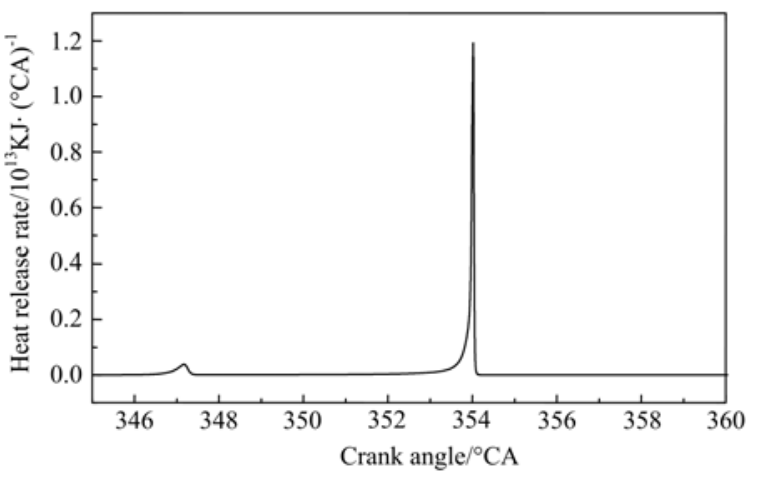

Figure 1. Heat release rate curve of isooctane HCCI combustion

Figure 2 shows the division of ignition time and combustion phase. The ignition points of lowtemperature reaction zone and high-temperature reaction zone correspon to the two combustion releasing heats. The combustion phase is divided into low-temperature reaction zone, high-temperature reaction zone and negative temperature coefficient (NTC) zone.

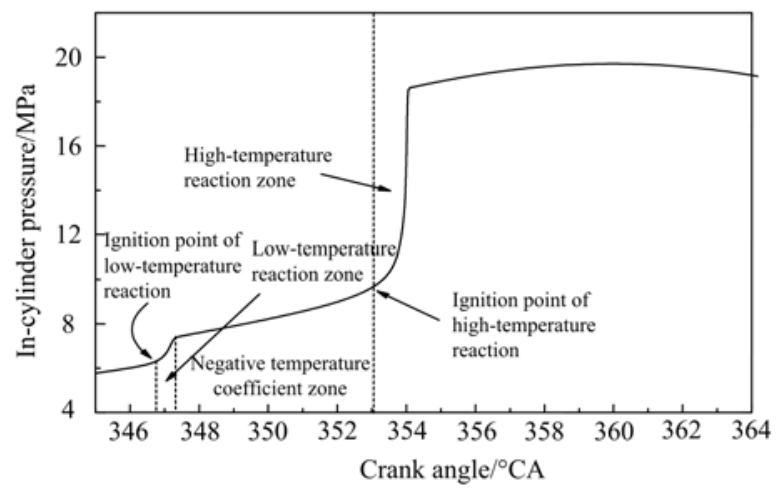

Figure 2. Division of ignition time and combustion phase 


\subsection{Impact analysis of compression ratio}

Figure 3 and Figure 4 show the effects of the compression ratio on combustor temperature and incylinder pressure. According to the observation, the compression ratio affects the temperature and pressure greatly. With the compression ratio improves, both the temperature and pressure increase continuously and the rates are slowed down. On the whole, the peaks of combustor temperature are always low in HCCI combustion model compare with the conventional diesel engine with the same operation condition. When the compression ratio exceeds 16 , the peak of combustor temperature has already over $2000 \mathrm{~K}$ that reached the level of conventional diesel engine.

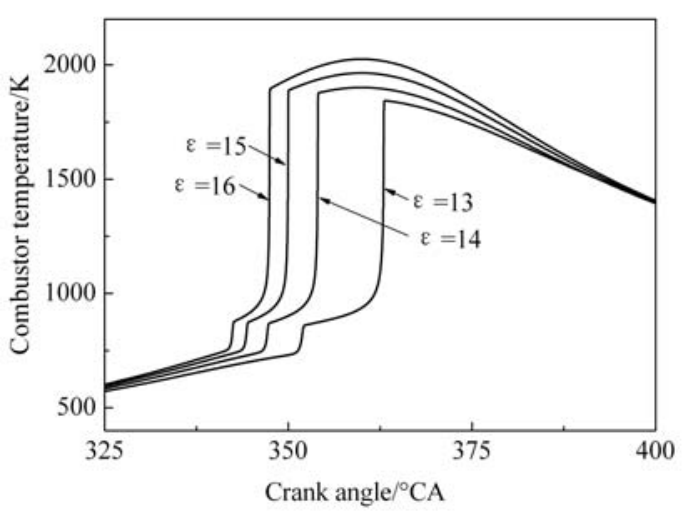

Figure 3. Effect of the compression ratio on combustor temperature

(Intake pressure $\mathrm{p}_{0}=0.25 \mathrm{MPa}$, intake air temperature $\mathrm{T}_{0}=320 \mathrm{~K}$, excess air coefficient $\lambda=2.8$.)

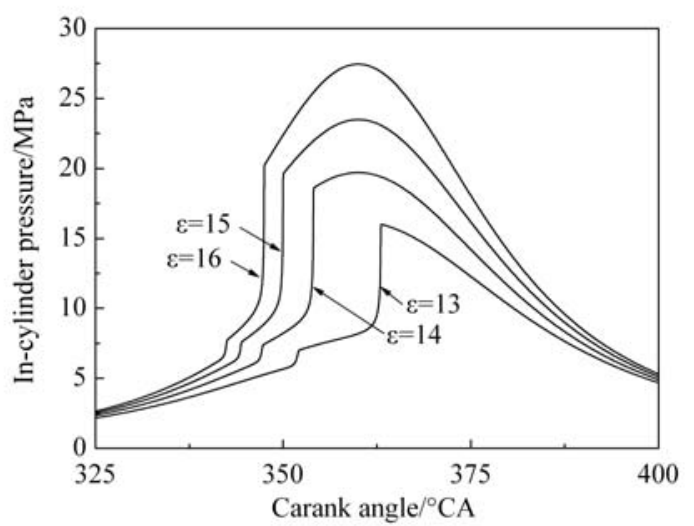

Figure 4. Effect of the compression ratio on in-cylinder pressure

(Intake pressure $\mathrm{p}_{0}=0.25 \mathrm{MPa}$, intake air temperature $\mathrm{T}_{0}=320 \mathrm{~K}$, excess air coefficient $\lambda=2.8$.)

The modern marine diesel engine commonly adopts high compression ratio that favorable for the thermal efficiency and fuel economical efficiency significantly. Due to the lower combustor temperature, the $\mathrm{NO}_{\mathrm{X}}$ emissions in HCCI combustion mode will be controlled effectively.

\subsection{Impact analysis of intake air temperature}

Figure 5 and Figure 6 show the effects of the intake air temperature on combustor temperature and in-cylinder pressure. With the rise of intake air temperature, the combustor temperature increases in the case of unchangeableness of the other initial conditions, but the max firing pressure slightly decreases. The ignition points of high-temperature reaction zone are brought forward with intake air temperature. These facts will promote the $\mathrm{NO}_{\mathrm{X}}$ emissions for the combustor temperature play important role in the chemical reaction rate of $\mathrm{NO}_{\mathrm{X}}$ formation [10].

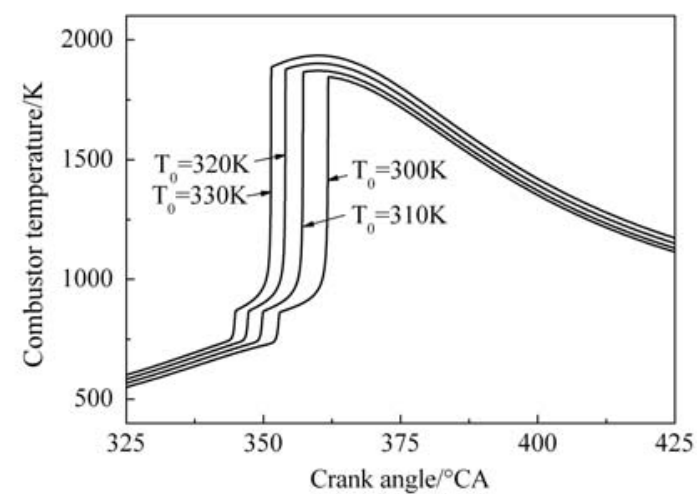

Figure 5. Effect of the intake air temperature on combustor temperature

(Intake pressure $\mathrm{p}_{0}=0.25 \mathrm{MPa}$, compression ratio $\varepsilon=13$, excess air coefficient $\lambda=2.8$.)

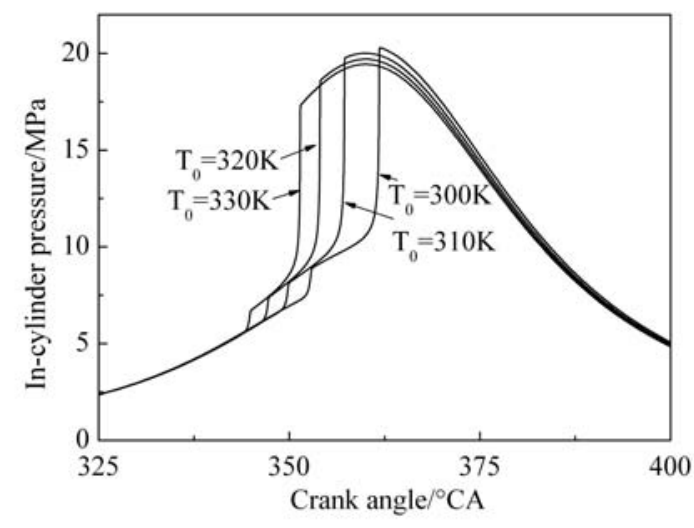

Figure 6. Effect of the intake air temperature on in-cylinder pressure

(Intake pressure $\mathrm{p}_{0}=0.25 \mathrm{MPa}$, compression ratio $\varepsilon=13$, excess air coefficient $\lambda=2.8$.)

\subsection{Impact analysis of intake pressure}

Figure 7 and Figure 8 show the effects of the intake pressure on combustor temperature and in-cylinder pressure. It is shown that the increase of intake pressure leads to rising of in-cylinder pressure, but the maximum combustor temperatures often remain about the same which have a relatively small impact on the $\mathrm{NO}_{\mathrm{x}}$ formations and emissions. Also, the ignition points of 
high-temperature reaction zone are brought forward with intake pressure that would extend the chemical reaction time of oxygen $\left(\mathrm{O}_{2}\right)$ and nitrogen $\left(\mathrm{N}_{2}\right)$ in high temperature zone.

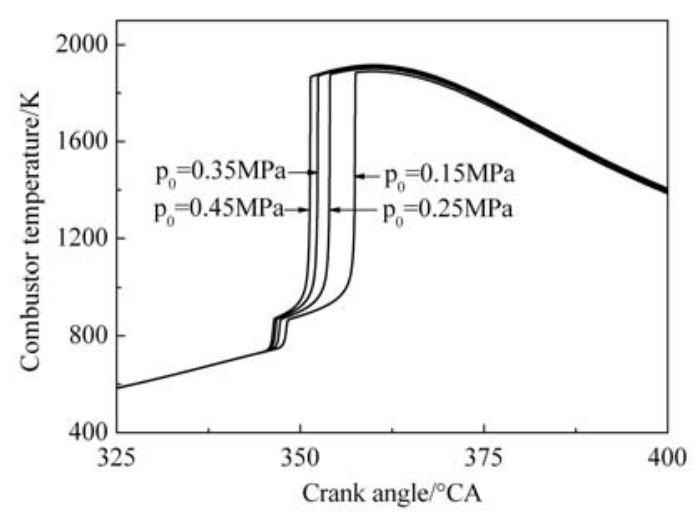

Figure 7. Effect of the initial pressure on combustor temperature

(Intake air temperature $\mathrm{T}_{0}=320 \mathrm{~K}$, compression ratio $\varepsilon=13$, excess air coefficient $\lambda=2.8$.)

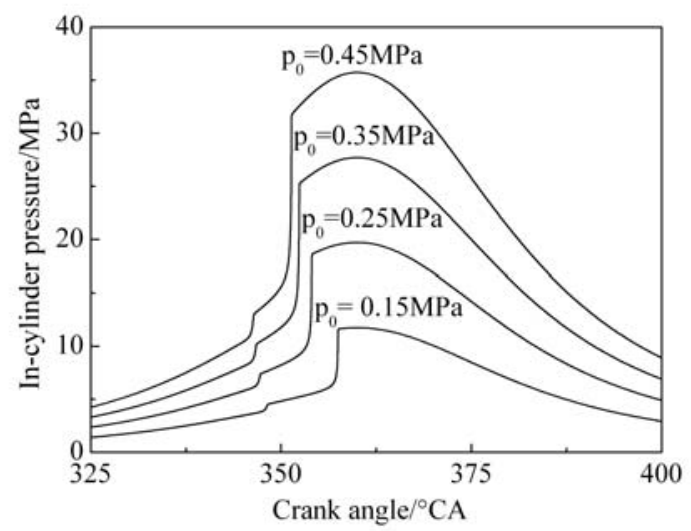

Figure 8. Effect of the initial pressure on in-cylinder pressure (Intake air temperature $\mathrm{T}_{0}=320 \mathrm{~K}$, compression ratio $\varepsilon=13$, excess air coefficient $\lambda=2.8$.)

\subsection{Impact analysis of excess air coefficient}

Figure 9 and Figure 10 show the effects of the excess air radio on combustor temperature and in-cylinder pressure. The simulation results confirm that, the impacts of excess air radio to the combustor temperature and in-cylinder pressure are remarkably. Overall, both the combustor temperature and in-cylinder pressure decrease with the increase of the excess air radio. The ignition points of high-temperature reaction zone are postponed that would decrease the chemical reaction time of oxygen $\left(\mathrm{O}_{2}\right)$ and nitrogen $\left(\mathrm{N}_{2}\right)$ in high temperature zone. These factors are not beneficial to the formations of $\mathrm{NO}_{\mathrm{X}}$. Related research also confirmed HCCI engines have extraordinarily lower $\mathrm{NO}_{\mathrm{X}}$ emissions with the dilute homogeneous air and fuel mixture. The $\mathrm{NO}_{\mathrm{X}}$ emissions of HCCI marine diesel engine can be controlled by adjusting the excess air radio.

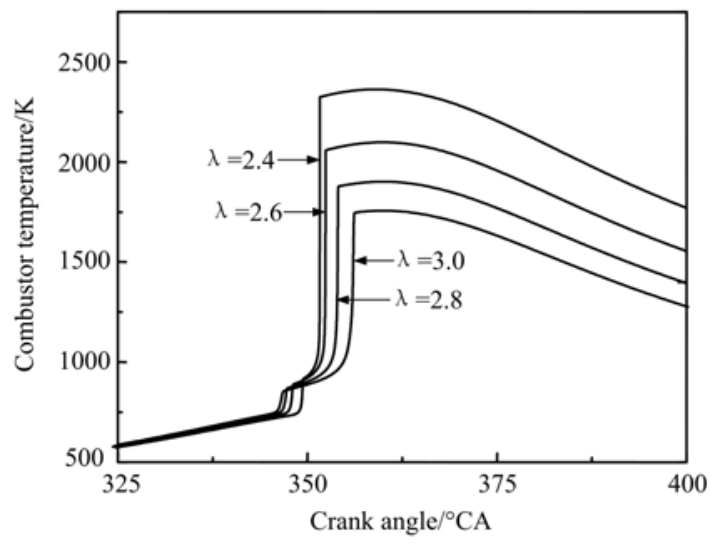

Figure 9. Effect of the excess air radio on combustor temperature

(Intake air temperature $\mathrm{T}_{0}=320 \mathrm{~K}$, intake pressure $\mathrm{p}_{0}=0.25 \mathrm{MPa}$, compression ratio $\varepsilon=13$.)

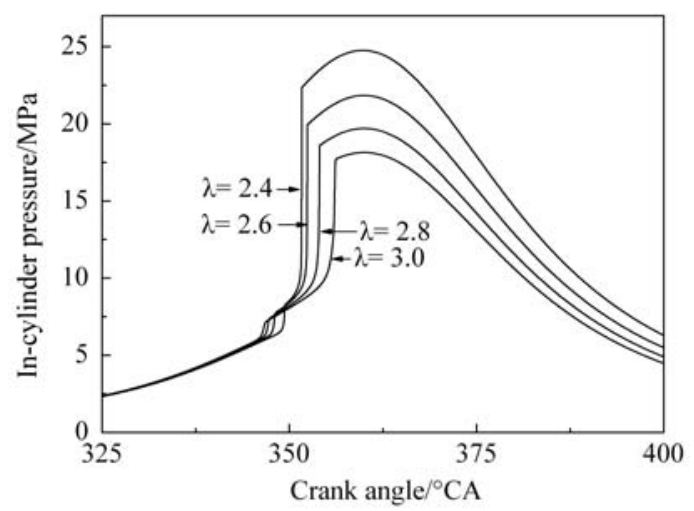

Figure 10. Effect of the excess air radio on in-cylinder pressure (Intake air temperature $\mathrm{T}_{0}=320 \mathrm{~K}$, intake pressure $\mathrm{p}_{0}=0.25 \mathrm{MPa}$, compression ratio $\varepsilon=13$.)

\section{Conclusions}

(1) Results from simulation confirm that HCCI combustion mode has the combustion releasing heats of low-temperature reaction and high-temperature reaction. The combustion phase is divided into low-temperature reaction zone, high-temperature reaction zone and negative temperature coefficient zone (NTC).

(2) The operating conditions of the high compression ratio, high intake air temperature, low inlet pressure and small excess air coefficient would cause the high incylinder pressure which often leads engine detonation.

(3) Applying HCCI combustion mode in marine diesel engine, the low compression ratio, low intake air temperature and big excess air coefficient would cause the low combustor temperature which is conducive to reduce $\mathrm{NO}_{\mathrm{X}}$ emissions. These technological means and operating conditions are expected to meet the $\mathrm{NO}_{\mathrm{X}}$ emissions limits in MARPOL73/78 Convention-Annex VI Amendment. 


\section{Acknowledgements}

This work was financially supported by the Research funds of the Maritime Safety Administration of the People's Republic of China (2012_27).

\section{References}

1. C. Yugma, J. Blue, S, Dauzère-Pérès, A, Obeid. Emission from international sea transportation and environmental impact, J. Geophys. Res. 108 (D17):129-144 (2003).

2. US EPA. Regulatory impact analysis: Control of emissions of air pollution from category 3 marine diesel engines, New York, (2009)

3. MAN Diesel \& Turbo. Emission project guide $M A N B \& W$ two-stroke marine engines, (2013)

4. L. Xue, C.H. Zhang, J. Wang. Cyclical variation of an HCCI engine fuelled by n-heptane. J. Chang'an Univ., 34 (6): 157-161 (2014)

5. M. Rashed, P.F.A. Macconnell, A.F. Stronach, P. Acarnley. Sensorless indirect-rotor-field-orientation speed control of a permanent-magnet synchronous motor with stator-resistance estimation. IEEE Transactions on Industrial Electronics, 54(3): 1664-1675 (2007)

6. S.K. Kim, Y.M. Kim. Prediction of detailed structure and $\mathrm{NO}_{\mathrm{X}}$ formation characteristics in turbulent non-premixed hydrogen jet flames. Combust. Sci. Technol., 156(1-6): 107-137 (2000)

7. Stephen R. Turns. An introduction to combustion: Concepts and Applications, McGRAW-HILL International Editions, (2000)

8. Z.L. Zheng, M.F. Yao. Numerical study on the chemical reaction kinetics of n-Heptane for HCCI combustion process. Trans. Csice, 22(3): 227-234 (2004)

9. L.P. Xu. The research of reducing the nitrogen oxide emission from marine diesel engine by wet inlet air with spraying water. Dalian: Dalian Maritime University, (2003)

10. W. Palmer. Cost-benefit study of marine engine $\mathrm{NO}_{\mathrm{X}}$ emissions control systems, A Case Study of the MV Cabot, 02, (2000) 